\title{
Quantification of Fusarium graminearum in Harvested Grain by Real-Time Polymerase Chain Reaction to Assess Efficacies of Fungicides on Fusarium Head Blight, Deoxynivalenol Contamination, and Yield of Winter Wheat
}

\author{
Y. J. Zhang, P. S. Fan, X. Zhang, C. J. Chen, and M. G. Zhou
}

College of Plant Protection, Nanjing Agricultural University, Nanjing 210095, China.

Accepted for publication 16 September 2008.

\begin{abstract}
Zhang, Y. J., Fan, P. S., Zhang, X., Chen, C. J., and Zhou, M. G. 2009. Quantification of Fusarium graminearum in harvested grain by real-time polymerase chain reaction to assess efficacies of fungicides on Fusarium head blight, deoxynivalenol contamination, and yield of winter wheat. Phytopathology 99:95-100.

We used a real time polymerase chain reaction-based assay and visual disease assessment to evaluate the efficacies of Js399-19, tebuconazole, a mixture of tebuconazole and thiram, azoxystrobin, carbendazim, and thiram on the development of Fusarium head blight (FHB) and deoxynivalenol (DON) contamination and on the yield of winter wheat (cv. Nannong no. 9918) after artificial inoculation under field conditions with Fusarium graminearum. The incidence of infected spikelets (IIS),

A strong positive correlation was found between IIS or $\log _{10}$ Tri5 DNA and total DON concentration in the harvested grain. The Js399-19, tebuconazole, and the mixture of tebuconazole and thiram significantly reduced IIS of FHB, amount of Tri5 DNA, and total DON within the grain and increased TGW. Although azoxystrobin, carbendazim, and thiram can increase TGW, they had no effect on the occurrence of $F$. graminearum compared with those of the untreated controls. Surprisingly, azoxystrobin and carbendazim significantly increased the total DON content in the harvested grain because they might have stimulated the amount of total DON production per Tri5 DNA. The fungicides Js399-19, tebuconazole, and the mixture of tebuconazole and thiram were the most effective in controlling FHB and reducing DON contamination of the wheat.
\end{abstract} amount of $F$. graminearum DNA (Tri5 DNA), total DON (containing DON, 3-acetyl-deoxynivalenol, and 15-acetyl-deoxynivalenol) concentration, and 1,000-grain weight (TGW) were quantified in 2006 and 2007.
Additional keyword: mycotoxins.
Fusarium head blight (FHB), also known as scab, is a destructive fungal disease of wheat and other small grain cereals throughout Europe (29), the United States (26), Canada (14), and China (4). Although 17 casual organisms have been associated with FHB (29), Fusarium culmorum and F. graminearum (teleomorph Gibberella zeae (Schwein.) Petch) are the species most commonly associated with the disease. In China, F. graminearum is the predominant species $(21,29)$. In recent years, yield loss in small grain cereals due to FHB epidemics has been estimated to be in the order of 10 to $70 \%$ (25). FHB epidemics occurred frequently in the middle and downstream regions of the Yangtze River and in the northeastern region in the past. However, with field climate change for high-yield culture, it has spread to the main wheat-production areas of northern and western China in the last decade.

The impact of FHB includes reducing cereal yield and grain quality as well as contaminating kernels with mycotoxins produced by Fusarium spp. Mycotoxin contamination causes the most serious economic concern because it can induce acute or chronic toxic effects when consumed by humans or livestock. Deoxynivalenol (DON) is the predominant trichothecene found in cereal grains in Europe, North America, and China (31,37). As a result, several countries have adopted advisory limits to ensure minimum levels of DON in finished products intended for human

Corresponding author: M. G. Zhou; E-mail address: mgzhou@njau.edu.cn

doi:10.1094/PHYTO-99-1-0095

(C) 2009 The American Phytopathological Society consumption. To safeguard human health, the People's Republic of China Ministry of Health advises a limit of $4 \%$ scabbed grains in wheat and less than $1 \mathrm{mg} \mathrm{kg}^{-1}$ for finished flour products (36). Similar guidelines have also been set for the United States $(1 \mathrm{mg}$ $\left.\mathrm{kg}^{-1}\right)$, European Union $\left(0.5 \mathrm{mg} \mathrm{kg}^{-1}\right)$, Austria $\left(0.5 \mathrm{mg} \mathrm{kg}^{-1}\right)$, and Canada $\left(2 \mathrm{mg} \mathrm{kg}^{-1}\right)(26)$.

At present, there are two major approaches to reducing DON contamination of grain: (i) application of fungicides at anthesis to reduce FHB (25) and (ii) selective breeding of cultivars resistant to Fusarium pathogens (28). In the absence of high levels of resistance within commercial wheat cultivars, most attempts to control FHB rely upon fungicide application. The curative systemic fungicide carbendazim, which belongs to benzimidazole group, is known to have a broad biological activity, including on Fusarium spp. on wheat plants. In China, this fungicide has been the most effective compound used to control FHB since the 1970s. Unfortunately, $F$. graminearum has developed serious resistance to carbendazim with a site-specific mode of action (39), leading to inefficacy of this fungicide. Fungicides containing triazoles as active ingredients are the most effective plant protection agents against Fusarium spp. at present (27) and considered to be an ideal substitute for carbendazim in China $(17,20)$. Nevertheless, resistance against triazoles was reported in Venturia inaequalis (22) and Mycosphaerella graminicola (35). Azoxystrobin, belonging to a relatively new group of fungicides, had been introduced for use on cereals in 1998. It is highly active against Microdochium nivale and saprophytic fungi (34) but has limited activity against Fusarium spp. (33). Moreover, a novel chemical, Js399-19 (2-cyano-3-amino-3-phenylancryic acetate), was devel- 
oped and used in China recently for controlling FHB (23). However, the effect of this fungicide on controlling FHB was evaluated just on the incidence of infected spikelets (IIS). The effect of it on DON contamination in the grain has not been reported.

Usually, evaluation of the effects of fungicides on controlling FHB mostly relied on the method of quantifying FHB pathogens. Current methods of quantifying FHB pathogens include (i) IIS (19), (ii) measure of fungal ergosterol (13), and (iii) detection of Tri5 DNA of Fusarium spp. by semiquantitative polymerase chain reaction $(\mathrm{PCR})(9,12)$. The first and second techniques estimate pathogen populations directly based on the incidence of the FHB pathogens which were a complex of Fusarium spp. and, therefore, non-species specific. Moreover, the third technique, based on conventional PCR, used an end-point measurement to quantify the amount of target DNA. Recently, a technique based on realtime PCR enabled calculation of the amount of PCR product present in a sample at a point of reaction in which strict exponentiality of DNA amplification has been described (11). Quantification of trichothecene-producing Fusarium spp. within harvested grain could be used to determine whether fungicides were affecting the proportion of trichothecene-producing $\mathrm{Fu}$ sarium spp. within the FHB complex and, hence, altering the relationship between FHB severity and the amount of DON in harvested grain.

Today, fungicides must be safe to the environment and humans before being authorized for use. Nevertheless, the benefits of such fungicide application are worth investigation in relation to their efficacy in preventing or reducing toxin synthesis under field conditions. The objectives of this study were to (i) develop a realtime PCR assay to quantify the amounts of $F$. graminearum Tri5 DNA within harvested grain; (ii) evaluate the efficacy of fungicides on FHB, total DON content, and the yield of wheat artificially inoculated with the same isolate of $F$. graminearum; and (iii) determine whether there was a correlation between IIS, quantity of Tri5 DNA, and total DON content.

\section{MATERIALS AND METHODS}

Fungal material. A single-spore culture of a strain ZF43, which was identified as wild-type of $F$. graminearum, isolated from a scabby wheat grain in Zhejiang Province of China, was maintained on potato-dextrose-agar slants or plates at $4{ }^{\circ} \mathrm{C}$ and used as needed. The ZF43 strain was highly pathogenic to winter wheat and had reliable levels of DON production (data not shown). For wheat head inoculation, conidia of $F$. graminearum were produced from a culture grown in $4 \%$ mung bean broth (1). The spore suspension was obtained by removing hyphal fragments through filtration and adjusted to a final concentration of $1 \times 10^{5}$ spores $\mathrm{ml}^{-1}$ of water using a hemacytometer (Arthur $\mathrm{H}$. Thomas Company, Philadelphia).
Field trial. During the 2006 growing season, winter wheat cv. Nannong No. 9918 was grown according to normal agronomic practices on Jiangpu Farm (Experiment Farm of Nanjing Agricultural University). Six fungicide treatments plus a control treatment without spraying were randomized in blocks $(2.5$ by $4.0 \mathrm{~m}$ for each plot of each replicate) according to a randomized block design with four replicates for each treatment. Plants were sprayed with the fungicides so that the solution was applied at $75 \mathrm{ml} / \mathrm{m}^{2}$ using a precision hand sprayer when plants were at ear emergence (Zadoks growth stage [ZGS] 59) (38). The fungicides and the doses used are described in Table 1 . When at midanthesis ZGS 65 (7 days after fungicide application), wheat spikes were artificially inoculated with the strain ZF43. Inoculation was achieved by spraying the prepared conidial suspension onto spikes using a knapsack sprayer at a rate of $33 \mathrm{ml} / \mathrm{m}^{2}$. Plots were mist irrigated for 21 days following inoculation to produce conditions conducive to FHB development (18). The above procedures were repeated in the same field in the growing season of 2007.

Visual disease assessment and yield determination. The IIS was determined visually by counting the number of infected spikelets per ear 3 weeks after inoculation. Fifty ears were randomly chosen and analyzed for each replicate of each fungicide treatment. Efficacy percentage was determined by applying Abbott's formula: (IIS of control - IIS of treated)/IIS of control $x$ 100. The wheat in the trial plots was harvested when ripe (ZGS 92) by hand threshing to ensure effective collection of all grains. A homogeneous $500-\mathrm{g}$ sample of grain at $13 \%$ moisture was taken from each plot and bulked to provide a $2-\mathrm{kg}$ sample per treatment. Four 50-g subsamples of grain were randomly selected to determine the weight ( $\mathrm{g}$ ) of 1,000 grains (TGW) of each fungicide treatment.

DNA extraction. DNA was extracted from pure fungal cultures using a modification of the method of Doohan et al. (8). A 3-dayold culture of $F$. graminearum in potato dextrose broth $\left(25^{\circ} \mathrm{C}\right.$, $160 \mathrm{rpm}$ ) was filtered through sterile muslin and freeze dried. The resultant mycelia $(0.5 \mathrm{~g})$ was frozen in liquid nitrogen and ground to fine powder in a mortar. Then, $1 \mathrm{ml}$ of cetyltrimethylammonium bromide (CTAB) buffer (sorbitol, $25 \mathrm{~g}$; CTAB, $8 \mathrm{~g}$; sodium chloride, $87 \mathrm{~g}$; polyvinylpolypyrrolidone,10 g; EDTA, $8 \mathrm{~g}$; sodium dodecyl sulfate, $10 \mathrm{~g}$; and water, 1 liter) was added to $100 \mathrm{mg}$ of the powder in a 2-ml Eppendorf tube, mixed, and incubated at $65^{\circ} \mathrm{C}$ for $2 \mathrm{~h}$. Following incubation, a $0.8-\mathrm{ml}$ aliquot of supernatant was removed and added to an equal volume of phenol-chloroform-isoamyl alcohol (25:24:1). The contents of the tubes were mixed by gentle inversion for $1 \mathrm{~min}$ and then centrifuged $(12,000 \times g)$ for $15 \mathrm{~min}$. A $0.65-\mathrm{ml}$ aliquot of the aqueous phase was removed to a fresh tube containing $0.65 \mathrm{ml}$ of $100 \%$ isopropanol. The contents of the tubes were mixed by gentle inversion for $1 \mathrm{~min}$, and the tubes were incubated at $4^{\circ} \mathrm{C}$ for $30 \mathrm{~min}$ and then centrifuged $(12,000 \times \mathrm{g})$ for $15 \mathrm{~min}$. The resulting DNA pellets were washed twice with $70 \%$ alcohol and then

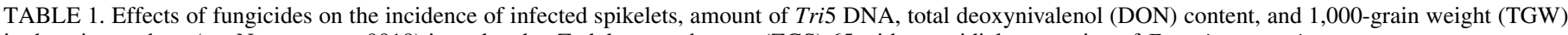
in the winter wheat (cv. Nannong no. 9918) inoculated at Zadoks growth stage (ZGS) 65 with a conidial suspension of Fusarium graminearum

\begin{tabular}{|c|c|c|c|c|c|c|c|c|c|c|c|c|c|}
\hline \multirow[b]{2}{*}{ Fungicide $^{\mathrm{y}}$} & \multirow{2}{*}{$\begin{array}{l}\text { Application } \\
\text { rate }\left(\mathrm{g} \text { a.i. } \mathrm{ha}^{-1}\right)\end{array}$} & \multicolumn{6}{|c|}{ Experiment $1(2006)^{\mathrm{z}}$} & \multicolumn{6}{|c|}{ Experiment $2(2007)^{\mathrm{z}}$} \\
\hline & & IIS & EIIS & ADNA & EADNA & TDON & TGW & IIS & EIIS & ADNA & EADNA & TDON & TGW \\
\hline Unsprayed control & & $30.6 \mathrm{a}$ & $\cdots$ & $279.1 \mathrm{a}$ & $\cdots$ & $9.3 \mathrm{a}$ & $32.5 \mathrm{~d}$ & $25.1 \mathrm{a}$ & & $228.6 \mathrm{a}$ & $\cdots$ & $7.7 \mathrm{a}$ & $39.9 \mathrm{~d}$ \\
\hline Thiram & 600 & $25.7 \mathrm{~b}$ & 16.2 & $228.9 \mathrm{~b}$ & 18.0 & $6.3 \mathrm{~b}$ & $35.5 \mathrm{~cd}$ & $21.2 \mathrm{~b}$ & 15.4 & $188.6 \mathrm{~b}$ & 17.9 & $5.2 \mathrm{~b}$ & $43.7 \mathrm{bc}$ \\
\hline Carbendazim & 375 & $19.3 \mathrm{c}$ & 37.2 & $153.9 \mathrm{c}$ & 44.8 & $9.1 \mathrm{a}$ & $38.9 \mathrm{bc}$ & $17.2 \mathrm{c}$ & 31.4 & $138.1 \mathrm{c}$ & 40.6 & $8.1 \mathrm{a}$ & $43.5 \mathrm{c}$ \\
\hline Tebuconazole & 125 & $7.7 \mathrm{~d}$ & 74.7 & $71.6 \mathrm{~d}$ & 74.3 & $1.3 \mathrm{c}$ & $44.7 \mathrm{a}$ & $7.1 \mathrm{e}$ & 71.8 & $64.9 \mathrm{e}$ & 73.5 & $1.2 \mathrm{c}$ & $46.3 \mathrm{ab}$ \\
\hline Azoxystrobin & 250 & $16.8 \mathrm{c}$ & 45.2 & $135.6 \mathrm{c}$ & 51.4 & $9.6 \mathrm{a}$ & $39.8 \mathrm{~b}$ & $13.8 \mathrm{~d}$ & 45.0 & $110.6 \mathrm{~d}$ & 53.0 & $7.8 \mathrm{a}$ & $44.7 \mathrm{abc}$ \\
\hline Js399-19 & 375 & $6.1 \mathrm{~d}$ & 80.2 & $33.6 \mathrm{e}$ & 87.9 & $1.1 \mathrm{c}$ & $45.1 \mathrm{a}$ & $5.4 \mathrm{f}$ & 78.5 & $29.4 \mathrm{f}$ & 89.5 & $1.0 \mathrm{c}$ & $47.3 \mathrm{a}$ \\
\hline Tebuconazole + thiram & 405 & $7.8 \mathrm{~d}$ & 74.5 & $62.2 \mathrm{de}$ & 77.7 & $1.5 \mathrm{c}$ & $44.7 \mathrm{a}$ & $7.5 \mathrm{e}$ & 70.2 & $59.0 \mathrm{e}$ & 76.1 & $1.5 \mathrm{c}$ & $46.9 \mathrm{a}$ \\
\hline
\end{tabular}

y All fungicides were commercially available and sprayed at ear emergence (ZGS 59).

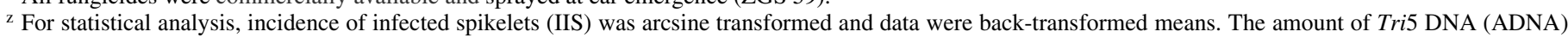
( $\mu \mathrm{g} \mathrm{kg}^{-1}$ of grain), total DON content (TDON) $\left(\mathrm{mg} \mathrm{kg}^{-1}\right.$ of grain) and TGW ( $\mathrm{g}$ ) did not require transformation. Data followed by the same letter were not significantly different ( $\mathrm{df}=18 ; P>0.05)$. Efficacy of fungicides on incidence of infected spikelets (EIIS) and amount of Tri5 DNA (EADNA) values was means of four replicates. 
air dried. Pellets were resuspended in $0.1 \mu \mathrm{l}$ of Tris-EDTA (TE) buffer $\left(10 \mathrm{mM}\right.$ Tris-HCl, $1 \mathrm{mM}$ EDTA, $\mathrm{pH} \mathrm{8.0)}$ at $65^{\circ} \mathrm{C}$ for $1 \mathrm{~h}$ before storage at $4^{\circ} \mathrm{C}$.

The method used for DNA extraction from grain samples was similar except that $20 \mathrm{ml}$ of CTAB buffer together with $50 \mu \mathrm{l}$ of proteinase $\mathrm{K}$ and $30 \mu \mathrm{l}$ of RNAase were added to $1 \mathrm{~g}$ of grain fine powder in a 50-ml centrifuge tube. DNA from grain was diluted 500 -fold in TE for use in a PCR amplification reaction. DNA content in $1 \mu$ l of DNA solution was equal to DNA content in $400 \mu \mathrm{g}$ of grain.

Primer design. Primers for Tri5 (primer Tr5F [AGCGACTACAGGCTTCCCTC] and primer Tr5R [AAACCATCCAGTTCTCCATCTG]), amplifying a 544-bp segment, were derived from conserved regions of Tri5 in F. graminearum (10). They were synthesized by Sangon (Shanghai, China) and purified by high-performance liquid chromatography. Lyophilized primers were dissolved in water to a concentration of $10 \mu \mathrm{M}$ and stored at $-20^{\circ} \mathrm{C}$.

Real-time quantitative PCR. PCR reactions were set up in 0.2-ml white opaque low-profile polypropylene tubes and covered with ultraclear caps (Bio-Rad Laboratories, Inc., Hercules, CA). Each tube contained $12 \mu \mathrm{l}$ of Platinum SYBR Green qPCR SuperMix-UDG (Invitrogen, Carlsbad, CA), $1 \mu$ of internal passive reference dye (reactive oxygen species), $1 \mu$ of primer mix (containing the forward and reverse primers, each at a concentration of $10 \mu \mathrm{M}$ ), and $1 \mu \mathrm{l}$ of either water (negative control) or template DNA. Distilled water was added to give a total volume of $25 \mu$ l. Forty-two samples were run in ABI PRISM 7000 PCR (Applied Biosystems, Foster City, CA) using the following cycling protocol. Samples were preheated at $50^{\circ} \mathrm{C}$ for $2 \mathrm{~min}$ followed by $2 \mathrm{~min}$ at $95^{\circ} \mathrm{C}$. Subsequently, 35 cycles of $15 \mathrm{~s}$ at $95^{\circ} \mathrm{C}, 30 \mathrm{~s}$ at $60^{\circ} \mathrm{C}$, and $45 \mathrm{~s}$ at $72^{\circ} \mathrm{C}$ were run. Detection of fluorescent product was carried out after the last step of each cycle. Following the final amplification cycle, a melting curve was acquired by one cycle of heating at $95^{\circ} \mathrm{C}$, cooling at $60^{\circ} \mathrm{C}$, and slowly heating at $95^{\circ} \mathrm{C}$ with continuous measurement of fluorescence at $520 \mathrm{~nm}$. The amount of Tri5 DNA (ADNA) present in a sample was calculated from a standard curve using the ABI PRISM 7000 software package (Applied Biosystems). The unit of the amount of Tri5 DNA present in grain sample was expressed as micrograms of Tri5 DNA per kilogram of grain $(\mu \mathrm{g}$ $\mathrm{kg}^{-1}$ of grain). Efficacy of fungicides on amount of Tri5 DNA was determined by applying the formula (ADNA of control - ADNA of treated)/ADNA of Tri5 DNA of control $\times 100$.

The standard curve was produced using the following method. First, purified $F$. graminearum DNA solution was determined by absorbance at $260 \mathrm{~nm}$ and the concentration of purified $F$. graminearum DNA solution was calculated from a calibration curve (11). Second, dilution series of purified $F$. graminearum DNA (from the concentration of 100 to $0.001 \mathrm{ng} / \mu \mathrm{l}$ ) was run on realtime PCR and threshold cycle (CT) values at which the amplification curves of each dilute solution crossing the crossing line were recorded. The crossing line was set manually to 19.60 and resulted in a standard curve with the lowest standard deviation. Third, the standard curve was generated by plotting these CT values as a function of logarithm values of the amount of fungal genomic DNA in series of dilution.

DON analysis. Trichothecene standards, including DON, 3acetyl-deoxynivalenol (3-ADON), and 15-acetyl-deoxynivalenol (15-ADON), were purchased form Sigma (Sigma-Aldrich, Shanghai, China). The method of extraction, clean-up, and derivatization for trichothecene analysis was modified from Goswami and Kistler (15). A 200-g subsample of grain was randomly selected form $2 \mathrm{~kg}$ of sample per treatment and ground for $5 \mathrm{~min}$ in an all-purpose grinder (Tianjin Traditional Chinese Medicine Machinery Factory, Tianjin, China). A 20 -g portion of ground fine sample was extracted for $1 \mathrm{~h}$ with $80 \mathrm{ml}$ of acetonitrile + water $(84+16, \mathrm{vol} / \mathrm{vol})$ on a reciprocating shaker. A 4 -ml extract was eluted through a 1 -g cleanup column containing C-18 + aluminum oxide $(3+1, \mathrm{wt} / \mathrm{wt})$. The elution was evaporated to dryness and derivatized with a trimethylsilylimidazole-rimethylchlorosilane mixture (100:1). The trimethylsilyl derivations of DON were identified and quantified using a Thermo Trace GC Ultra capillary column gas chromatograph equipped with an auto injector (AS3000), electron capture detector, and MN Permabond SE-54-DF-0.25 (30 $\mathrm{m}$ by $0.25 \mathrm{~mm}$ interior diameter, film thickness $0.28 \mu \mathrm{m}$ (Macherey-Nagel, Düren, Germany). The temperatures of the injection port and the detector were 250 and $300^{\circ} \mathrm{C}$, respectively. The column temperature was $80^{\circ} \mathrm{C}$ held for $1 \mathrm{~min}$, $40^{\circ} \mathrm{C} \mathrm{min}^{-1}$ to $160^{\circ} \mathrm{C}$ held for $1 \mathrm{~min}$, and then $30^{\circ} \mathrm{C} \mathrm{min}^{-1}$ to $280^{\circ} \mathrm{C}$ held for $5 \mathrm{~min}$. The carrier gas was helium at flow rate of $1.08 \mathrm{ml} \mathrm{min}^{-1}$. The experiment of toxin extraction and analysis was repeated three times.

Statistical analysis. All data were analyzed with the analysis of variance and means were separated with the Fisher's protected least significant difference test at $P=0.05$ to determine whether fungicide had a significant effect on IIS, quantity of Tri5 DNA, DON content, and TGW. Where data were not normally distributed, appropriate transformations were performed prior to analysis. Simple linear regression analysis was also performed in order to determine whether significant relationships existed between IIS, quantity of Tri5 DNA, and DON content. All data analysis was carried out using the statistical software SAS GLM (SAS Institute Inc., Cary, NC).

\section{RESULTS}

Similar results were recorded for each fungicide treatment from the two experiments, although there was significant difference between the two sets of data $(P<0.001)$ (Table 1$)$. Therefore, data from the two experiments are presented separately. Across all fungicide treatments, results obtained from experiment 2 revealed lower IIS, concentrations of Tri5 DNA, and DON in harvested grain compared with results obtained from experiment 1. However, TGW of 2007 was greater than that of 2006. This may be explained by the difference in weather conditions when the two experiments were performed. The curve of air temperature during the trial in 2007 paralleled the curve in 2006 but the precipitation during the trial in 2007 was significantly lower compared with 2006. Therefore, weather in 2006 was more favorable to FBH disease development than in 2007 (Fig. 1).

Fungicide effects on IIS. All fungicides reduced significantly $(P<0.05)$ the IIS caused by $F$. graminearum compared with the untreated controls (Table 1). Of all fungicides tested, Js399-19, tebuconazole, and a mixture of tebuconazole and thiram at 1:4 provided the most effective control of FHB and was significantly $(P<0.05)$ better than all other treatments. However, statistical analysis revealed that there was a significant difference $(P<0.05)$ between Js399-19 and tebuconazole in experiment 2 (2007). Although applications of thiram, carbendazim, and azoxystrobin also significantly reduced IIS compared with the untreated controls, the percent control achieved was only 15.4 to $45.2 \%$.

Fungicide effects on quantity of Tri5 DNA. The standard curve achieved by plotting CT values against the logarithm values of the amount of fungal genomic DNA gave a linear relationship $(y=-2.58 x+20.73, r=0.98)$ over the range of DNA concentrations examined. The detection limit of the assay was determined to be $1 \mathrm{pg}$ of genomic DNA per reaction. No signal was measured in the uncontaminated wheat sample used as negative control. All samples amplified at the recommended concentration (shown in DNA extraction method) resulted in CT values within the range of the purified $F$. graminearum DNA standards. The real-time PCR assay employed to quantify the trichothecene-producing gene Tri5 revealed that concentrations of Tri5 DNA in harvested grain were significantly $(P<0.05)$ lower when plants were treated with all fungicides compared with the untreated 
controls (Table 1). The Js399-19 fungicide proved to be the most effective, providing $87.9 \%$ (experiment 1 ) and $89.5 \%$ (experiment 2) control on Tri5 DNA in harvested grain. However the mixture of tebuconazole and thiram at 1:4 and tebuconazole alone were less effective on reducing Tri5 DNA than Js399-19, with reductions in 2006 and 2007 of 76.1 and $77.7 \%$ and 73.5 and $74.3 \%$, respectively. Of all fungicides, applications of thiram, carbendazim, or azoxystrobin were the least effective in decreasing Tri5 DNA though they also significantly reduced Tri5 DNA when compared with the untreated controls.

Fungicide effects on total DON, 3-ADON, and 15-ADON concentration in the grains. The gas chromatograph quantified the combined concentrations of DON, 3-ADON, and 15-ADON in harvested grain. Detection limits as assessed with pure reference substances at a signal-to-noise ratio of $3: 1$ were 25,40 , and $20 \mu \mathrm{g} \mathrm{kg}^{-1}$ for DON, 3- ADON, and 15-ADON, respectively. No signal was measured in the uncontaminated wheat sample used as negative control. The amounts of total DON in the wheat inoculated with $F$. graminearum ranged from 1.0 to $9.6 \mathrm{mg} \mathrm{kg}^{-1}$ of grain. Js399-19, the mixture of tebuconazole and thiram at 1:4, tebuconazole, and thiram alone could significantly $(P<0.05)$ reduce the concentration of total DON compared with the untreated controls (Table 1), with reductions of 87.0 to $88.2 \%, 84.4$ to $86.0 \%, 80.5$ to $83.9 \%$, and 32.2 to $32.5 \%$, respectively. Statistical analysis revealed that there was not a significant difference $(P<0.05)$ between Js399-19, the mixture of tebuconazole and thiram, and tebuconazole. Applications of azoxystrobin and carbendazim had no significant effect on the DON concentration. In contrast, both azoxystrobin and carbendazim slightly increased the total DON content.

Fungicide effects on TGW. All fungicides significantly increased TGW in 2006 and 2007, except thiram, which did not raise the TGW significantly $(P<0.05)$ compared with the untreated controls in experiment 1 (2006) (Table 1). Of all fungicides tested, Js399-19, tebuconazole alone, and the mixture of tebuconazole and thiram at 1:4 provided the greatest increase of TGW (increasing TGW by 18.5 and $38.8,17.5$ and 37.5 , and 16.0 and $37.5 \%$ for 2006 and 2007, respectively). Statistical analysis revealed no evidence of a significant difference between the enhancements of TGW achieved from treatments of Js399-19, tebuconazole, and the mixture of tebuconazole and thiram.

Relationship between IIS, quantity of Tri5 DNA, and total DON content. Regression analysis revealed a significant $(P<$ $0.05)$ linear relationship between IIS and total DON content or $\log _{10}$ Tri5 DNA and total DON content in the grains (Fig. 2). For each fungicide, it was seen that an increase of IIS or $\log _{10}$ Tri5 DNA resulted in concomitant increase in total DON content in the grains. However, the correlation coefficients between $\log _{10}$ Tri5
DNA and total DON content in seven fungicide treatments were higher than IIS and total DON content. In addition, linear equations $(y=a x+b)$ between IIS or $\log _{10}$ Tri5 DNA and total DON content in seven treatments shown that the slopes $(a)$ for Js399-19, tebuconazole alone, and the mixture of tebuconazole and thiram were obviously lower than those for azoxystrobin, carbendazim, and unsprayed control.

\section{DISCUSSION}

Previous work had shown that incidence of infected spikelets of FHB and DON concentration in harvested grains may $(3,16)$ or may not be closely correlated $(12,24)$. We found a good and positive correlation between IIS of FHB and DON concentration in harvested grains. However, fungicidal control of FHB had proved inconsistent, and conflicting evidence existed regarding the effect of fungicides on the IIS of FHB and the mycotoxin accumulation in grain infected by Fusarium spp. In most cases, both FHB and DON content were reduced following fungicide application (3). However, in some instances, reduction of one variable was not accompanied by reduction of the other (3). In certain instances, fungicide treatments led to an increase DON levels in grain despite a reduction in disease severity (33). Results from this study showed that Js399-19, tebuconazole plus thiram, and tebuconazole alone were very effective on both IIS of FHB and DON concentration in harvested grains. However azoxystrobin was not effective on $F$. graminearum and resulted in a slight increase in total DON concentration in harvested grains. The results can be explained by the differences among azoxystrobin, tebuconazole, and Js399-19 in fungicidal activity against members of the fungal complex causing FHB. Azoxystrobin is known to be active against $M$. nivale (33), and tebuconazole and Js39919 were shown to be very active against $F$. graminearum and other Fusarium spp. $(23,33)$.

Similar to the instance of the IIS of FHB, Js399-19, tebuconazole plus thiram, and tebuconazole alone were very effective in decreasing the amount of Tri5 DNA of F. graminearum. Linear regression analysis revealed a strong correlation between the biomass of $F$. graminearum and DON concentration in harvested grains. Such results were consistent with those from other researchers $(9,12,32)$. Moreover we also found that the correlation coefficients between $\log _{10}$ Tri5 DNA and total DON content in seven fungicide treatments were higher than those between IIS of FHB and total DON content. This may be due to the fact that the quantification of $F$. graminearum in harvested grain by Tri5 DNA was more accurate than the IIS. In addition, the amount of $F$. graminearum in the harvested grain determined the amount of DON concentration in the same conditions. However, the linear
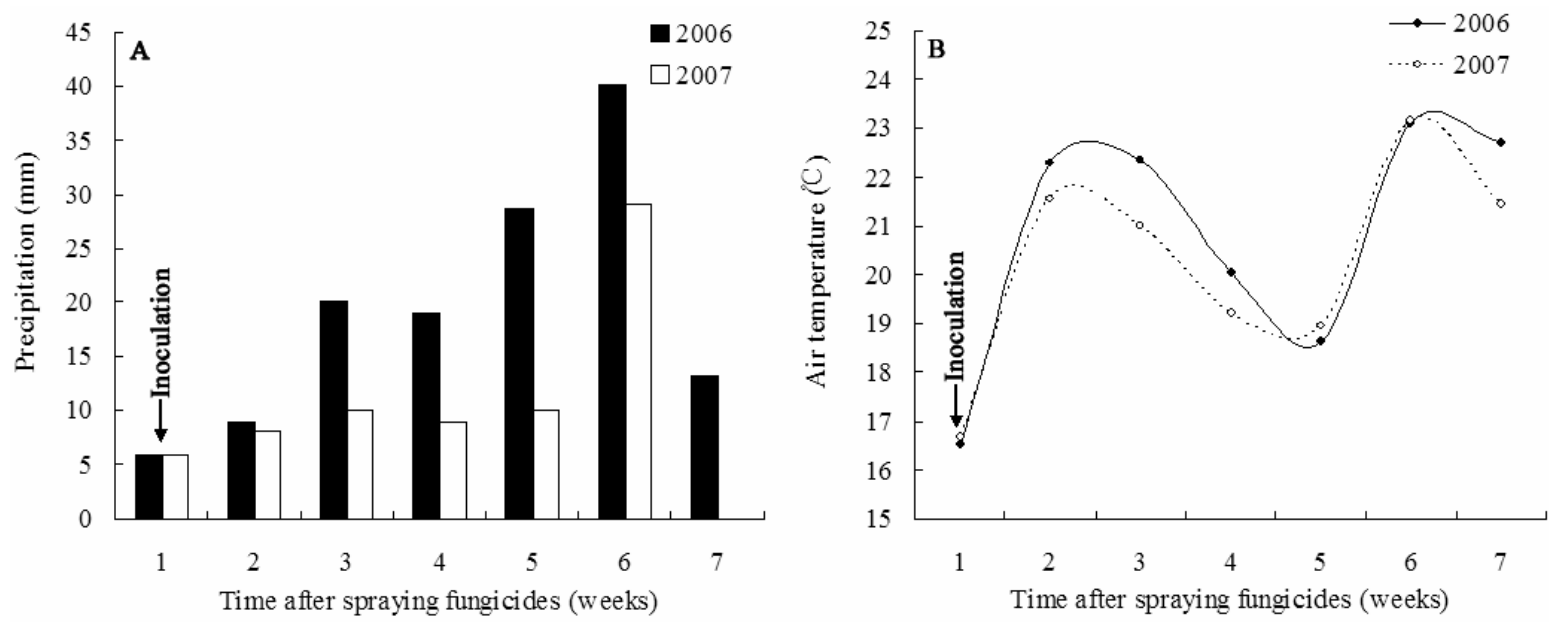

Fig. 1. Weather data (weekly average) for Jiangpu Farm of Nanjing Agricultural University during the trial. A, Precipitation and $\mathbf{B}$, air temperature. 
equations between IIS or $\log _{10}$ Tri5 DNA and total DON content in seven treatments were different. The slopes for Js399-19, tebuconazole alone, and the mixture of tebuconazole and thiram were obviously lower than those for azoxystrobin, carbendazim, and unsprayed control. It seemed that fungicide Js399-19, tebuconazole alone, and the mixture of tebuconazole and thiram could reduce the efficiency of DON production per unit of pathogen, whereas azoxystrobin and carbendazim increased this efficiency. The results of applying tebuconazole were consistent with those reported in earlier studies $(12,30)$, yet the results about azoxystrobin were also consistent with the ones from other studies $(7,33)$. The results on the effect of Js399-19, carbendazim, and thiram on DON production are considered new findings. To prove whether fungicides can alter the efficiency of DON production per unit of pathogen, we can also determine the efficiency of
DON production per unit of Tri5 mRNA in $F$. graminearum by fungicide treatments in vitro (6) or in vivo.

A number of researchers had reported that most fungicide treatments could raise the yield of wheat compared with untreated control. Results from field experiments in our study showed that all fungicide treatments increased the TGW. The results for tebuconazole and azoxystrobin were consistent with those from other researchers $(2,16)$. However, of all tested fungicides, Js39919 was the most effective in increasing TGW.

Results from the survey suggested that the excellent effect of carbendazim on FHB has been reduced, and the azoxystrobin fungicide had the least effect on F. graminearum. Moreover, azoxystrobin and carbendazim significantly increased DON contamination in harvested grains. Therefore, there is a challenge now to find alternative fungicides, and carbendazim and azoxy-
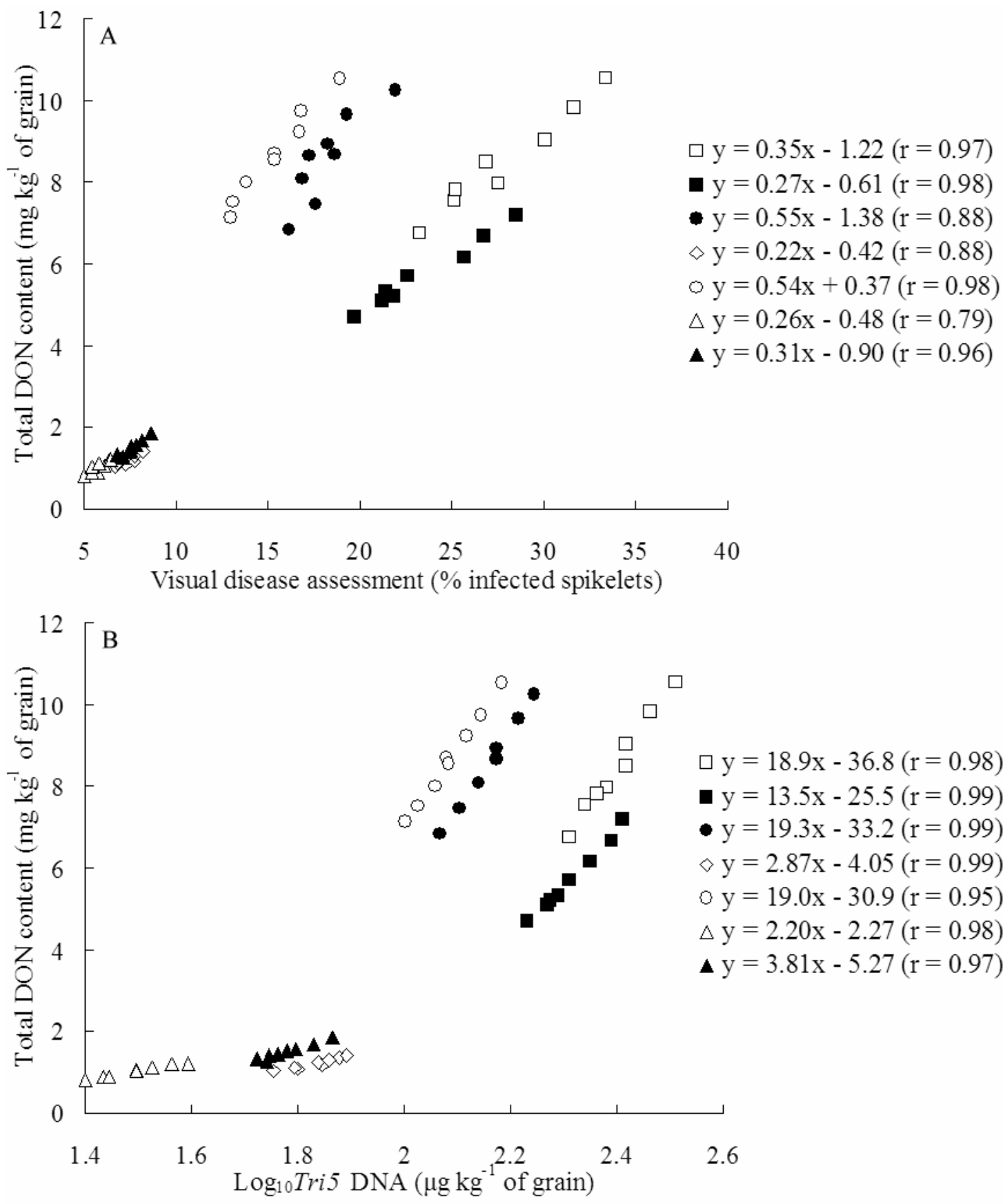

Fig. 2. Relationship between A, visual disease assessment (percent infected spikelets) and B, quantity of Tri5 DNA ( $\log _{10}$ Tri5 DNA) and total deoxynivalenol $(\mathrm{DON})$ content in harvested grain of winter wheat (cv. Nannong no. 9918) from field plots sprayed with thiram $(\mathbf{\square})$, carbendazim $(\bullet)$, azoxystrobin $(0)$, tebuconazole $(\diamond)$, Js399-19 $(\Delta)$, or a mixture of tebuconazole + thiram $(\mathbf{\Delta})$ at Zadoks growth stage $59 ; \square=$ unsprayed control plot. 
strobin should not be used in China, where $F$. graminearum is the predominant species causing FHB. To date, Js399-19 has been shown to be the most effective fungicide, because it can effectively reduce the IIS of FHB, Tri5 DNA, and total DON contamination in wheat. Furthermore, it can also raise the weight of grain. Therefore, the fungicide Js399-19 might replace carbendazim for controlling FHB in the future in China, particularly in the areas where a carbendazim-resistant pathogen population have been detected (23). However, similarly to carbendazim, the Js399-19 fungicide also might be problematic due to high resistance risk, because $F$. graminearum isolates can easily produce resistance to it in vitro (5). Therefore, a practical recommendation should be that Js399-19 be applied alternately with tebuconazole or mixed with other fungicides. These strategies can manage the resistance risk and sustain the usefulness of this new product for the control of FHB.

\section{ACKNOWLEDGMENTS}

This work was funded by the State Programs of "973" (no. 2006CB101907) and Science and Technology Support (2006BAE01A0408 and 2006BAD08A03) from the Ministry of Science and Technology of China, and Jiangsu Provincial Program for Tackling Key Problems of Science and Technology (no. BG2006328).

\section{LITERATURE CITED}

1. Bai, G. H., and Shaner, G. 1996. Variation in Fusarium graminearum and cultivar resistance in wheat scab. Plant Dis. 80:975-979.

2. Bertelsen, J. R., De-Neergaard, E., and Smedegaard-Petersen, V. 2001. Fungicidal effects of azoxystrobin and epoxiconazole on phyllosphere fungi, senescence and yield of winter wheat. Plant Pathol. 50:190-205.

3. Boyacioglu, D., Hettiarachchy, N. S., and Stack, R. W. 1992. Effects of three systemic fungicides on deoxynivalenol (vomitoxin) production by Fusarium graminearum in wheat. Can. J. Plant Sci. 72:93-101.

4. Chen, L. F., Bai, G. H., and Desjardins, A. E. 2000. Recent advances in wheat head scab research in China. Published online by the National Agricultural Library.

5. Chen, Y., Chen, C. J., Wang, J. X., Jin, L. H., and Zhou, M. G. 2007. Induction and characterization of nitrate nonutilizing mutants of Fusarium graminearum resistant to fungicide Js399-19. Sci. Agric. Sin. 40:735-740.

6. Covarelli, L., Turner, A. S., and Nicholson, P. 2004. Repression of deoxynivalenol accumulation and expression of Tri genes in Fusarium culmorum by fungicides in vitro. Plant Pathol. 53:22-28.

7. D’Mello, J. P. F., Macdonald, A. M. C., Postel, D., Dijksma, W. T. P., Dujardin, A., and Placinta, C. M. 1998. Pesticide use and mycotoxin production in Fusarium and Aspergillus phytopathogens. Eur. J. Plant Pathol. 104:741-751.

8. Doohan, F. M., Parry, D. W., Jenkinson, P., and Nicholson, P. 1998. The use of species-specific PCR-based assays to analyse Fusarium ear blight of wheat. Plant Pathol. 47:197-205.

9. Doohan, F. M., Parry, D. W., and Nicholson, P. 1999. Fusarium ear blight of wheat: The use of quantitative PCR and visual disease assessment in studies of disease control. Plant Pathol. 48:209-217.

10. Doohan, F. M., Weston, G., Rezanoor, H. N., Parry, D. W., and Nicholson, P. 1999. Development and use of a reverse transcription PCR assay to study expression of Tri5 by Fusarium species in vitro and in planta. Appl. Environ. Microbiol. 65:3850-3854.

11. Dyer, R. B., Kendra, D. F., and Brown, D. W. 2007. Real-time PCR assay to quantify Fusarium graminearum wild-type and recombination mutant DNA in plant material. J. Microbiol. Methods 67:534-542.

12. Edwards, S. G., Pirgozliev, S. R., Hare, M. C., and Jenkinson, P. 2001. Quantification of trichothecene-producing Fusarium species in harvested grain by competitive PCR to determine efficacies of fungicides against Fusarium head blight of winter wheat. Appl. Environ. Microbiol. 67:1575-1580.

13. Gilbert, J., Abramson, D., McCallum, B., and Clear, R. 2001. Comparison of Canadian Fusarium graminearum isolates for aggressiveness, vegetative compatibility, and production of ergosterol and mycotoxins. Mycopathologia 153:209-215.

14. Gilbert, J., and Tekauz, A. 2000. Recent developments in research in Fusarium head blight of wheat in Canada. Can. J. Plant Pathol. 22:1-8.

15. Goswami, R. S., and Kistler, H. C. 2005. Pathogenicity and in planta mycotoxin accumulation among members of the Fusarium graminearum species complex on wheat and rice. Phytopathology 95:1397-1404.
16. Haidukowski, M., Pascale, M., Perrone, G., Pancaldi, D., Campagna, C., and Visconti, A. 2004. Effect of fungicides on the development of Fusarium head blight, yield and deoxynivalenol accumulation in wheat inoculated under field conditions with Fusarium graminearum and Fusarium culmorum. J. Sci. Food Agric. 82:191-198.

17. Han, Q. M., Kang, Z. S., and Duan, S. K. 2003. The control effects of two fungicides, tebuconazole and metconazole to Fusarium head blight of wheat. Acta Phytophylacica Sin. 30:339-440.

18. Hilton, A. J., Jenkinson, P., Hollins, T. W., and Parry, D. W. 1999. Relationship between cultivar height and severity of Fusarium ear blight in wheat. Plant Pathol. 48:202-208.

19. Hormdock, S., Fehrmann, H., and Beck, R. 2000. Effects of field application of tebuconazole on yield, yield components and the mycotoxin content of Fusarium infected wheat grain. J. Phytopathol. 148:1-6.

20. Ioos, R., Belhadj, A., Menez, M., and Faure, A. 2005. The effects of fungicide on Fusarium spp. and Microdochium nivale and their associated trichothecene mycotoxins in French naturally-infected cereal grains. Crop Prot. 24:894-902.

21. Ji, L., Cao, K., Hu, T., and Wang, S. 2007. Determination of deoxynivalenol and nivalenol chemotypes of Fusarium graminearum isolates from China by PCR assay. J. Phytopathol. 155:505-512.

22. Kunz, S., DeIISng, H., and Mendgen, K. 1997. Acquisition of resistance to sterol demethylation inhibitors by populations of Venturia inaequalis. Phytopathology 87:1272-1278.

23. Li, H. K., Diao, Y. M., Wang, J. X., Chen, C. J., Ni, J. P., and Zhou, M. G. 2008. Js399-19, a new fungicide against wheat scab. Crop Prot. 27:273278.

24. Liu, W. Z., Langseth, W., Skinnes, H., Elen, O. N., and Sundheim, L. 1997. Comparison of visual head blight ratings, seed infection levels, and deoxynivalenol production for assessment of resistance in cereals inoculated with Fusarium culmorum. Eur. J. Plant Pathol. 10:589-595.

25. Matthies, A., and Buchenauer, H. 2000. Effect of tebuconazole (Folicur) and prochloraz (Sportac) treatments on Fusarium head scab development, yield and deoxynivalenol (DON) content in grains of wheat following artificial inoculation with Fusarium culmorum. J. Plant Dis. Prot. 107:3352.

26. McMullen, M., Jones, R., and Gallenberg, D. 1997. Scab of wheat and barley: a re-emerging disease of devastating impact. Plant Dis. 81:13401348 .

27. Mesterhazy, A., Bartok, T., and Lamper, C. 2003. Influence of wheat cultivar, species of Fusarium, and isolate aggressiveness on the efficiency of fungicides for control of Fusarium head blight. Plant Dis. 87:11071115 .

28. Mesterhazy, A., Bartok, T., Mirocha, C. G., and Komoroczy, R. 1999. Nature of wheat resistance to Fusarium head blight and the role of deoxynivalenol for breeding. Plant Breed. 118:97-110.

29. Parry, D. W., Jenkinson, P., and McLeod, L. 1995. Fusarium ear blight (scab) in small grain cereals - A review. Plant Pathol. 44:207-238.

30. Pirgozliev, S. R., Edwards, S. G., Hare, M. C., and Jenkinson, P. 2002. Effect of dose rate of azoxystrobin and metconazole on the development of Fusarium head blight and the accumulation of deoxynivalenol (DON) in wheat grain. Eur. J. Plant Pathol. 108:469-478.

31. Placinta, C. M., D’Mello, J. B. F., and Macdonald, A. M. C. 1999. A review of world contamination of cereal grains and animal feed with Fusarium mycotoxins. Anim. Feed Sci. Technol. 78:21-37.

32. Schnerr, H., Vogel, R. F., and Niessen, L. 2002. Correlation between DNA of trichothecene-producing Fusarium species and deoxynivalenol concentrations in wheat-samples. Lett. Appl. Microbiol. 35:121-125.

33. Simpson, D. R., Weston, G. E., Turner, J. A., Jennings, P., and Nicholson, P. 2001. Differential control of head blight pathogens of wheat by fungicides and consequences for mycotoxin contamination of grain. Eur. J. Plant Pathol. 107:421-431.

34. Siranidou, E., and Buchenauer, H. 2001. Chemical control of Fusarium head blight on wheat. J. Plant Dis. Prot. 108:231-243.

35. Stergiopoulos, I., Van-Nistelroy, J. G. M., Kema, G. H. J., and De-Waard, M. A. 2003. Multiple mechanisms account for variation in base-line sensitivity to azole fungicides in field isolates of Mycosphaerella graminicola. Pest Manage. Sci. 59:1333-1343.

36. Sui, K., Li, J., Wei, F., and Zhao, S. C. 2005. Determination of deoxynivalenol in cereal grains by high performance liquid chromatography and verified by high performance liquid chromatography-mass spectrometry. Chin. J. Anal. Chem. 33:1643-1646.

37. Wang, Y. Z., and Miller, J. D. 1994. Toxin producing potential of Fusarium graminearum from China. Acta Mycol. Sin. 13:229-234.

38. Zadoks, J. C., Chang, T. T., and Konzak, C. F. 1974. A decimal code for the growth stages of cereals. Weed Res. 14:415-421.

39. Zhou, M. G., and Wang, J. X. 2001. Study on sensitivity base-line of $F$. graminearum to carbendazim biological characters of $\mathrm{MBC}$-resistant strains. Acta Phytopathol. Sin. 31:365-370. 